\title{
Hormonal and cognitive factors associated with the exploratory behavior of rats submitted to repeated sessions of the elevated plus-maze
}

\author{
Lucas Albrechet-Souza and Marcus L. Brandão \\ Universidade de São Paulo, Brazil
}

\begin{abstract}
Naive rats submitted to the elevated plus-maze (EPM) display a characteristic increase in open arm exploration and reduced risk assessment behaviors (RABs) after the administration of anxiolytic drugs. Upon re-exposure to the maze, however, the traditional measures of the EPM become resistant to these drugs. This intriguing phenomenon was initially observed for the benzodiazepine chlordiazepoxide and referred as one-trial tolerance (OTT). In this review, we summarized hormonal, cognitive and neuroanatomical data obtained from rats submitted to the test/retest protocol in the EPM. The re-exposure to the EPM is characterized by more prominent RABs and a distinct Fos protein distribution in the brain, particularly in limbic structures involved with the cognitive aspects of fear, such as the ventral regions of the medial prefrontal cortex (mPFC) and amygdala. Interestingly, naive rats treated with midazolam had a significant decrease in the number of Fos-positive neurons in the anterior cingulate cortex, area $1(\mathrm{Cg} 1)$, anterior and dorsal premammillary nuclei of hypothalamus. On the other hand, midazolam caused a significant decrease in the number of Fos-positive neurons in the mPFC, amygdala, dorsomedial nucleus of hypothalamus and raphe nuclei in maze-experienced rats. $\mathrm{Cg} 1$ was the only structure targeted by the benzodiazepine in both sessions. Systemically administered midazolam before test or retest sessions reduced the RABs and plasma corticosterone levels in rats submitted to both sessions. Similar behavioral results were obtained with intra- $\mathrm{Cg} 1$ infusions of midazolam. The results reviewed here support the view of the crucial role of the RABs in the development of the OTT and point to this mPFC area as an important locus for the anxiolytic-like action of benzodiazepines in rodents. Keywords: elevated plus-maze, retest session, benzodiazepines, corticosterone, Fos expression, anterior cingulate cortex.
\end{abstract}

Received 25 November 2009; received in revised form 11 January 2010; accepted 11 January 2010. Available on line 25 June 2010

\section{Introduction}

The elevated plus-maze (EPM) is one of the most popular animal models of anxiety currently in use. The test, validated for rats (Handley \& Mithani, 1984; Pellow, Chopin, File, \& Briley, 1985) and mice (Lister, 1987), is based on the natural aversion of rodents to open spaces, which leads to a conflict between the exploration of new environments and avoidance to the open arms. It has also been suggested that the preference for the closed arms is derived from the possibility of thigmotaxis so as the avoidance of the open arms occurs primarily because

Lucas Albrechet-Souza, Instituto de Neurociências \& Comportamento - IneC, Universidade de São Paulo, São Paulo, Brazil. Marcus L. Brandão, Laboratório de Psicobiologia, Faculdade de Filosofia, Ciências e Letras de Ribeirão Preto, Universidade de São Paulo, Ribeirão Preto, Brazil. Correspondence regarding this article should be directed to: Lucas Albrechet-Souza, Instituto de Neurociências \& Comportamento INeC, Campus USP, Av. Bandeirantes, 3900, Ribeirão Preto, São Paulo, Brazil, CEP 14040-901. Phone: +55-16-3602-3837. Fax: +55-16-3602-4830. E-mail: lucasas@pg.ffclrp.usp.br they do not allow the rats to engage in thigmotaxic behavior (Treit, Menard, \& Royan, 1993). It is likely that the popularity of the EPM test is due to its obvious and numerous advantages, namely: economy, rapidity, simplicity of design and bidirectional drug sensitivity, coupled with the fact that it does not require lengthy training procedures or the use of food/water deprivation or electric shocks (Carobrez \& Bertoglio, 2005; Pellow et al., 1985; Rodgers, Cao, Dalvi, \& Holmes, 1997).

Rodents tested in the EPM display a characteristic decrease of anxiety-related behaviors after the administration of anxiolytic-like drugs. The increase in the activity in the open arms of the maze and the reduction of risk assessment behaviors (RABs) have been taken as good indices of the anxiolytic-like action of the benzodiazepines (Albrechet-Souza, Borelli, Carvalho, \& Brandão, 2009; Bertoglio, Anzini, Linode-Oliveira, \& Carobrez, 2005; Pellow et al., 1985). However, when rats or mice are tested twenty four hours or even two weeks later for a second time on the maze, this anxiolytic effect is much reduced or absent (Albrechet-Souza et al., 2005; Bertoglio \& Carobrez, 
2000; Carvalho, Albrechet-Souza, Masson, \& Brandão, 2005; Cruz-Morales, Santos, \& Brandão, 2002; File, Mabbutt, \& Hitchott, 1990; Lister, 1987). The failure of these compounds in attenuating the traditional behavioral categories in maze-experienced rodents, initially observed for the benzodiazepine chlordiazepoxide, is referred as one-trial tolerance (OTT) (File, 1990).

Several hypotheses have been proposed to explain the OTT phenomenon, such as locomotor habituation (Dawson, Crawford, Stanhope, Iversen, \& Tricklebank, 1994), an altered state of the binding-site on the GABA-benzodiazepine receptors (Gonzalez \& File, 1997), an experimentally induced sensitization of fear/anxiety (Bertoglio \& Carobrez, 2000; Treit et al., 1993) and a qualitative shift in the emotional state between trials, from an unconditioned fear response to a learned avoidance (Bertoglio \& Carobrez, 2003; DalCól et al., 2003; Holmes \& Rodgers, 1998). We have recently shown that during the retest session occurs the activation of cognitive-related telencephalic structures involved in the control of learned fear (AlbrechetSouza, Borelli, \& Brandão, 2008). After the initial overall apparatus exploration it seems that such rodents acquire, consolidate and retrieve some kind of memory related to the exploration of potentially dangerous open areas of the maze (Bertoglio \& Carobrez, 2002; CruzMorales et al., 2002; File, 1993; File, Zangrossi, Viana, \& Graeff, 1993). It was also found that rodents continue to respond to the benzodiazepines on the retest session when a new motivational conflict is introduced during the task (Pereira, Vieira, Konishi, Ribeiro, \& FrussaFilho, 1999). Similar reinstatement of the anxiolyticlike actions of the benzodiazepines also occurs when the first exposure length in the EPM is limited to 1 or extended to 10 minutes (Dal-Cól et al., 2003; File et al., 1993), amnesic doses of chlordiazepoxide (File et al., 1990), scopolamine (Bertoglio \& Carobrez, 2004) or propranolol (Stern, Carobrez, \& Bertoglio, 2008) are administered prior to first exposure and intraamygdala infusions of benzodiazepine receptor agonist and antagonist are conducted prior to retest (Barbalho, Canto-de-Souza, \& Nunes-de-Souza, 2009).

More recently, the conventional analysis of the exploratory behavior in the EPM was extended to incorporate the so-called novel ethological categories which have disclosed additional dimensions to EPM behavior patterns, for example, vertical activity, directed exploration, decision making and RABs (Cole \& Rodgers, 1993). The biological function of the risk assessment acts and postures is to monitor behavioral strategies in potentially dangerous situations (Blanchard, Blanchard, \& Rodgers, 1991; Blanchard, Yudko, Rodgers, \& Blanchard, 1993). Rodents continue to display enhanced RABs even after ceasing to avoid, for example, an unprotected area, suggesting that this defensive pattern may even be more sensitive to anxiety- modulating drugs than avoidance-related measures (Griebel, Rodgers, Perrault, \& Sanger, 1997; Rodgers, 1997; Rodgers \& Cole, 1994; Setem, Pinheiro, Motta, Morato, \& Cruz, 1999).

\section{Hypothalamic-pituitary-adrenal (HPA) axis and EPM test}

The activation of the HPA axis is considered part of the stress reaction and is triggered either by innate or learned fear stimuli (File, Zangrossi, Sanders, \& Mabbutt, 1994; Rodgers et al., 1999). In response to stressful events, the corticotropin-releasing factor (CRF) is released from the median eminence of the hypothalamus, which activates the adrenocorticotropin hormone (ACTH) secretion. The increase of ACTH into the bloodstream consequently acts at the adrenal cortex to facilitate the release of glucocorticoids such as corticosterone in rodents (Risbrough \& Stein, 2006; Rivier, Grigoriadis, \& Rivier, 2003; Vale, Spiess, Rivier, \& Rivier, 1981).

Pellow et al. (1985), in their now classic article on the validation of the EPM as a model of anxiety in rats, reported that confinement to either an open or an enclosed arm of the maze produced a significant increase in plasma corticosterone relative to home-cage controls. Moreover, the corticosterone response to the open areas of the maze was significantly greater than that to the enclosed arms. Other subsequent studies have confirmed this hormonal activation in rats submitted to the EPM test (Mikics, Barsy, Barsvari, \& Haller, 2005; Rodgers et al., 1999) and shown that rats re-exposed to the EPM remain with high levels of plasma corticosterone, supporting the idea that this hormonal response does not appear to habituate with retest and the animals continue

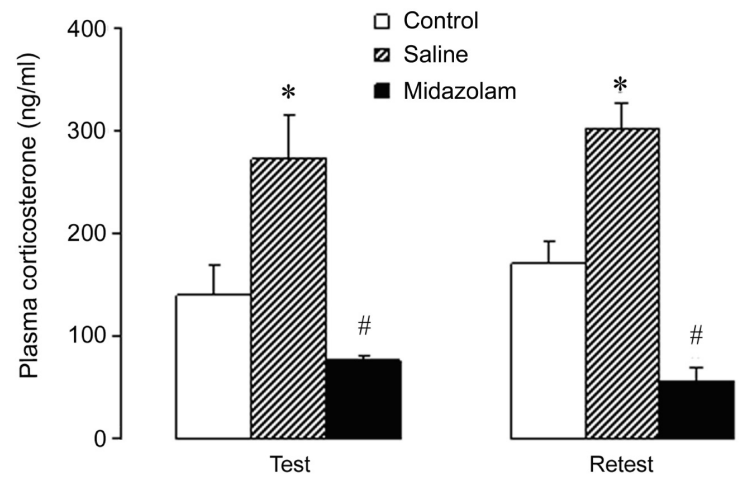

Figure 1. Plasma corticosterone levels of rats systemically treated with saline or midazolam $.5 \mathrm{mg} / \mathrm{kg}$ and, after 15 minutes, submitted to the EPM test or retest sessions (intertrial interval was $24 \mathrm{~h}$ ). Control group of the test session was not submitted to the EPM and control group of the retest session was tested in the EPM $24 \mathrm{~h}$ before the collection of the blood sample. The values are mean + SEM. * different from the control group in the same session, and \# different from the saline group in the same session $(\mathrm{p}<.05$, ANOVA followed by Duncan's test). $n=6-8$ rats in each group. 
under the influence of a stressful situation (AlbrechetSouza, Carvalho, Franci, \& Brandão, 2007; File et al., 1994; Rodgers et al., 1999).

The corticosterone response was also found to be positively correlated with measures of RABs, but not with measures of open arms or general locomotor activity (Albrechet-Souza et al., 2007; Mikics et al., 2005; Rodgers et al., 1999). Then, the key behavioral association with the corticosterone response to the maze appears to be aborted attempts to enter the open arms rather than the actual exploration of these potentially threatening areas (Rodgers et al., 1999). In line with this statement, the treatment with the benzodiazepine midazolam had an anxiolytic effect on the RABs and counteracted the increase in plasma corticosterone levels in rats submitted to the EPM test and retest sessions (Figure 1) (Albrechet-Souza et al., 2007).

Once the RABs are normally taken during the ongoing experimental session and the steroid response about twenty minutes after the end of the test, it seems that the higher the level of RABs the larger the glucocorticoid response. Thus, this hormonal activation appears to be based not on the actual exploration of the stressful environment (Pellow et al., 1985), but rather, in the detection of the danger. In the same way, in humans, anticipation of threatening events produces as marked an elevation in cortisol as the event itself (Mason, 1968). In view of growing evidence from animal and human studies for the involvement of glucocorticoids in cognitive function (De Quervain, Roozendaal, \& McGaugh, 1998; Roozendaal, Bohus, \& McGaugh, 1996), it is tempting to speculate on the potential involvement of the corticosterone in the emotional learning that is characteristic of the EPM paradigm (Holmes \& Rodgers, 1998).

The neuropeptide CRF has also been implicated in the regulation of endocrine, behavioral and autonomic responses to stress, fear and anxiety. Experimental evidence has demonstrated that its intracerebroventricular administration increases RABs in mice submitted to the Mouse Defensive Test Battery (Yang, Farrokhi, Vasconcellos, Blanchard, \& Blanchard, 2006). Besides, CRF has a selective action in the dorsomedial column of the periaqueductal gray matter (DMPAG), since injections of ovine CRF in this area (and not in other PAG columns) promote a clear anxiogenic-like effect in rats submitted to the EPM (Borelli \& Brandão, 2008). This functional role of the DMPAG in the organization of avoidance behaviors was suggested in a study in which this area was the only mesencephalic region with significant Fos immunoreactivity in rats submitted to a place avoidance paradigm (Zanoveli, Ferreira-Netto, \& Brandão, 2007). Obviously, the involvement of the $\mathrm{CRF}$ in other components of the defensive system remains open to investigation.

\section{Cognition and the EPM test}

Factor analyses have been used in the EPM research to identify the relationship between specific test indices and factor/dimensions such as anxiety, locomotor activity, risk assessment and decision making (AlbrechetSouza et al., 2008; Anseloni \& Brandão, 1997; File et al., 1993; Rodgers \& Johnson, 1995 ). In this context, the emotional state produced upon re-exposure to the EPM seems to be qualitatively different to that produced on the initial exposure because the traditional measures taken in these sessions were found to load in separate factors (Albrechet-Souza et al., 2008; File et al., 1993). In addition, the re-exposure to the EPM is characterized by a more prominent RABs (stretched-attend posture, peeping out and flat-back approach), since these categories compounded a factor that loaded before the factor with the RABs of the first session (Table 1) (Albrechet-Souza et al., 2008). These findings support the idea that the EPM may be a model where the nature, rather than the extent, of the emotional state changes with the experience of the maze (File et al., 1993) and the RABs may reinstate the information-processing initiated during the first experience in the novel environment of the EPM. The detection of danger associated with this behavioral strategy probably gives way to the strong open arm avoidance of the retest session (AlbrechetSouza et al., 2007). This interpretation reconciles well with the fact that RABs are associated with avoidance behavior since they are expressed from the closed towards the open arms of the maze.

\section{Distinct neural circuits of the naive and maze- experienced rats submitted to the EPM test}

Mapping of neural circuits using the Fos proteinimmunoreactivity technique showed that the divergent behavioral patterns displayed in the test and retest conditions are associated with the activation of distinct brain areas (Albrechet-Souza et al., 2008). Naive rats submitted to the EPM showed activation of essentially limbic structures such as the cingulate cortex $1(\mathrm{Cg} 1)$, paraventricular (PVN) and dorsomedial nuclei (DMH) of hypothalamus and mesencephalic areas (AlbrechetSouza et al., 2008; Silveira, Sandner, \& Graeff, 1993) whereas re-exposure to the EPM recruits mainly areas involved in cognitive aspects of fear, such as the ventral regions of the medial prefrontal cortex (mPFC) and its projection areas such as the amygdala (Figure 2). These structures are much more activated in the retest session than in the test session (Table 2 - saline groups) (Albrechet-Souza et al., 2008).

The mPFC - which includes the anterior cingulate, prelimbic and infralimbic cortex (Singewald, 2007) - is considered an interface between emotional and cognitive functions and its ventral aspects project to 
Table 1. Orthogonal factor loadings for behavioral categories of rats submitted to EPM test and retest sessions. Behavioral categories (SAP, peeping out and flat-back) grouped as RABs loaded on factor 3 (retest session) and factor 4 (test session). Factor loadings $<.5$ are not included. Criteria: Eigenvalue $\geq 1$. EAE, end arm exploration; SAP, stretched-attend posture. For a complete description of the behavioral categories, see Albrechet-Souza et al., 2008.

\begin{tabular}{|c|c|c|c|c|c|c|}
\hline & $\mathrm{F} 1$ & $\mathrm{~F} 2$ & $F 3$ & $F 4$ & F5 & F6 \\
\hline \multicolumn{7}{|l|}{ Test Session } \\
\hline Closed entries & & & & & .61 & \\
\hline$\%$ Closed entries & -.86 & & & & & \\
\hline Time closed arms & -.95 & & & & & \\
\hline$\%$ Time closed arms & -.95 & & & & & \\
\hline Open entries & .95 & & & & & \\
\hline$\%$ Open entries & .86 & & & & & \\
\hline Time open arms & .96 & & & & & \\
\hline \%Time open arms & .96 & & & & & \\
\hline Total arms entries & .82 & & & & & \\
\hline$\%$ Time center & .72 & & & & & \\
\hline EAE & .92 & & & & & \\
\hline Scanning & & & & .80 & & \\
\hline Head dipping & .79 & & & & & \\
\hline Rearing & & & & & .87 & \\
\hline Peeping out & & & & .57 & & \\
\hline SAP & & & & .70 & & \\
\hline Flat-back approach & & & & .63 & & \\
\hline Grooming & & & & & & -.88 \\
\hline \multicolumn{7}{|l|}{ Retest session } \\
\hline Closed entries & & & .57 & & & \\
\hline$\%$ Closed entries & & -.90 & & & & \\
\hline Time closed arms & & -.94 & & & & \\
\hline \%Time closed arms & & -.94 & & & & \\
\hline Open entries & & .94 & & & & \\
\hline$\%$ Open entries & & .90 & & & & \\
\hline Time open arms & & .98 & & & & \\
\hline \%Time open arms & & .98 & & & & \\
\hline Total arms entries & & .58 & & & & \\
\hline$\%$ Time center & & .75 & & & & \\
\hline EAE & & .89 & & & & \\
\hline Scanning & & & .76 & & & \\
\hline Head dipping & & .60 & & & & \\
\hline Rearing & & & .83 & & & \\
\hline \multicolumn{7}{|l|}{ Peeping out } \\
\hline SAP & & & .84 & & & \\
\hline \multicolumn{7}{|l|}{ Flat-back approach } \\
\hline Grooming & & & & & & -.70 \\
\hline
\end{tabular}


the amygdala and hypothalamic areas (Heidbreder \& Groenewegen, 2003). It has also been proposed to be involved in fear conditioning (Holschneider et al., 2006; Milad, \& Quirk, 2002; Morgan \& LeDoux, 1995; Pezze, Bast, \& Feldon, 2003; Vouimba, Garcia, Baudry, \& Thompson, 2000; ). In fact, lesions of ventral $\mathrm{mPFC}$ have an effect on the extinction but not on the acquisition phase of a fear conditioning task (Morgan, Romanski, \& LeDoux, 1993) and lesions of its dorsal aspects lead to increased fear responses during fear conditioning acquisition and extinction (Morgan \& LeDoux, 1995). Thus, these data support the view of the $\mathrm{mPFC}$ as a functionally heterogeneous area involved in various aspects of fear conditioning.
Behavioral studies have also demonstrated that the mPFC exerts a marked influence on the expression of defensive responses (Siegel \& Chabora, 1971; Siegel, Edinger, \& Lowenthal, 1974) and a functional magnetic resonance imaging study in humans showed that this area has a key role in the controllability of fear states engendered by activation of more caudal structures (Mobbs et al., 2007).

Altogether, these data suggest that the re-exposure to the EPM is related to a learned avoidance, with the predominance of a cognitive aspect of the fear. It is characterized by a more prominent RABs associated with a brain differential activity. In view of these results we recently suggested the re-exposure to the EPM

Table 2. Number of Fos-immunoreactive cells $/ 0.1 \mathrm{~mm}^{2}$ (mean $\pm \mathrm{SEM}$ ) in rats systemically treated with saline or midazolam $.5 \mathrm{mg} / \mathrm{kg}$ and submitted to the EPM test or retest sessions. Control group was not exposed to the EPM. * compared to control group; § compared to saline group in the test session; \# compared to saline group in the same session ( $\mathrm{p}<.05$, ANOVA followed by Duncan's test). $n=5-8$ rats in each group.

\begin{tabular}{|c|c|c|c|c|c|}
\hline \multirow[b]{2}{*}{ Brain areas } & \multirow[b]{2}{*}{ Control } & \multicolumn{2}{|c|}{ Test Session } & \multicolumn{2}{|c|}{ Retest Session } \\
\hline & & Saline & Midazolam & Saline & Midazolam \\
\hline \multicolumn{6}{|c|}{ Telencephalon } \\
\hline $\mathrm{Cg} 1$ & $30.6 \pm 3.6$ & $60.8 \pm 7.7^{*}$ & $43.0 \pm 5.8 \#$ & $70.3 \pm 6.0^{*}$ & $57.3 \pm 4.8 \#$ \\
\hline $\mathrm{Cg} 2$ & $8.6 \pm 1.8$ & $17.2 \pm 4.1$ & $15.7 \pm 1.5$ & $37.5 \pm 8.8^{*} \S$ & $18.7 \pm 2.3 \#$ \\
\hline PrL & $8.1 \pm 0.9$ & $21.4 \pm 5.2$ & $19.1 \pm 4.7$ & $44.8 \pm 6.9 * \S$ & $20.8 \pm 3.1 \#$ \\
\hline IL & $6.6 \pm 0.9$ & $13.6 \pm 3.3$ & $10.8 \pm 2.9$ & $28.4 \pm 6.0 * \S$ & $15.4 \pm 2.7 \#$ \\
\hline CA1 & $6.5 \pm 1.4$ & $6.5 \pm 2.9$ & $5.4 \pm 0.6$ & $5.9 \pm 2.2$ & $8.5 \pm 2.0$ \\
\hline CA2 & $7.7 \pm 2.7$ & $5.2 \pm 1.7$ & $7.8 \pm 1.5$ & $6.1 \pm 1.6$ & $8.9 \pm 2.1$ \\
\hline CA3 & $4.4 \pm 1.9$ & $2.3 \pm 1.0$ & $4.7 \pm 0.4$ & $4.8 \pm 1.8$ & $7.1 \pm 0.6$ \\
\hline BLA & $7.2 \pm 1.1$ & $9.8 \pm 2.4$ & $9.3 \pm 0.9$ & $23.3 \pm 4.0 * \S$ & $11.8 \pm 1.9 \#$ \\
\hline $\mathrm{CeA}$ & $9.9 \pm 1.1$ & $14.9 \pm 4.0$ & $14.5 \pm 1.4$ & $29.8 \pm 4.4^{*} \S$ & $11.2 \pm 1.7 \#$ \\
\hline $\mathrm{MeA}$ & $9.0 \pm 1.3$ & $15.1 \pm 3.8$ & $17.0 \pm 2.4$ & $18.5 \pm 1.8$ & $18.8 \pm 3.0$ \\
\hline \multicolumn{6}{|c|}{ Hypothalamus } \\
\hline PVN & $21.4 \pm 3.1$ & $36.1 \pm 4.0^{*}$ & $42.5 \pm 4.0$ & $37.7 \pm 3.6^{*}$ & $31.0 \pm 2.4$ \\
\hline $\mathrm{AHC}$ & $23.3 \pm 4.7$ & $31.0 \pm 1.6$ & $20.7 \pm 3.3 \#$ & $23.1 \pm 3.5$ & $21.2 \pm 2.4$ \\
\hline $\mathrm{DMH}$ & $22.5 \pm 3.1$ & $32.9 \pm 3.1^{*}$ & $31.2 \pm 3.3$ & $31.6 \pm 1.7^{*}$ & $16.9 \pm 1.0 \#$ \\
\hline PMD & $14.5 \pm 2.8$ & $32.9 \pm 6.8$ & $17.9 \pm 4.5 \#$ & $20.2 \pm 3.9$ & $13.4 \pm 2.7$ \\
\hline \multicolumn{6}{|l|}{ Brainstem } \\
\hline DMPAG & $25.3 \pm 5.9$ & $23.1 \pm 1.9$ & $23.9 \pm 2.5$ & $18.0 \pm 1.7$ & $21.3 \pm 1.0$ \\
\hline DLPAG & $13.2 \pm 3.3$ & $13.4 \pm 2.1$ & $17.8 \pm 1.7$ & $12.4 \pm 1.4$ & $14.5 \pm 1.7$ \\
\hline LPAG & $16.0 \pm 2.2$ & $21.6 \pm 1.3$ & $22.6 \pm 1.9$ & $19.3 \pm 2.2$ & $21.6 \pm 0.8$ \\
\hline VLPAG & $21.3 \pm 3.0$ & $21.2 \pm 1.1$ & $17.4 \pm 2.1$ & $25.1 \pm 3.4$ & $17.5 \pm 2.2$ \\
\hline $\mathrm{IC}$ & $8.9 \pm 1.1$ & $17.6 \pm 2.8^{*}$ & $14.5 \pm 2.0$ & $22.3 \pm 3.0^{*}$ & $16.0 \pm 1.8$ \\
\hline DRN & $18.9 \pm 3.9$ & $19.8 \pm 60$ & $15.1 \pm 2.2$ & $28.8 \pm 6.0$ & $16.5 \pm 3.0 \#$ \\
\hline $\mathrm{MnR}$ & $13.0 \pm 2.5$ & $13.6 \pm 2.3$ & $10.6 \pm 1.8$ & $12.5 \pm 1.3$ & $7.3 \pm 1.1 \#$ \\
\hline $\mathrm{LC}$ & $9.0 \pm 2.3$ & $12.5 \pm 0.5$ & $13.5 \pm 3.4$ & $14.8 \pm 1.5$ & $13.1 \pm 1.3$ \\
\hline
\end{tabular}




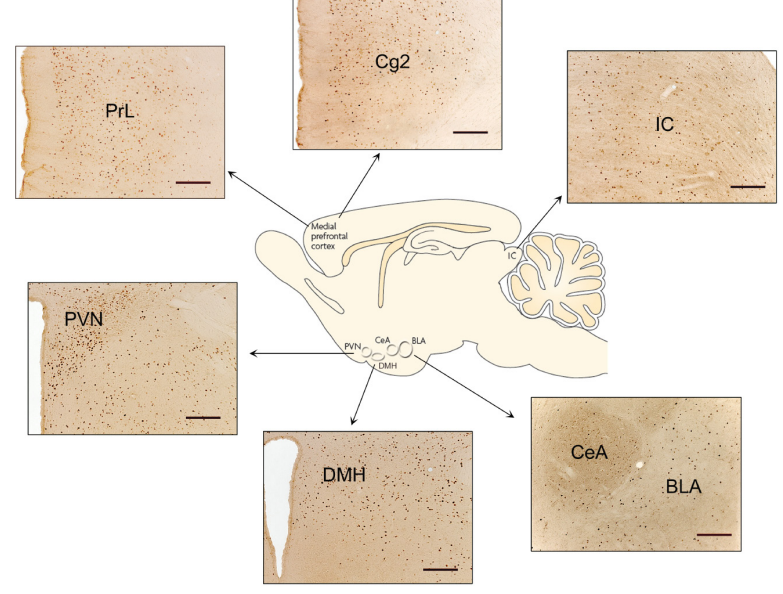

Figure 2. Schematic representation of the rat brain illustrating the structures activated during the EPM retest session. The insets are coronal photomicrographs of the indicated areas showing Fos-immunoreactive neurons (dark dots). Bar represents $200 \mu \mathrm{m}$ in all photomicrographs. BLA, basolateral amygdaloid nucleus; $\mathrm{CeA}$, central amygdaloid nucleus; $\mathrm{Cg} 2$, cingulate cortex, area 2; DMH, dorsomedial hypothalamus; IC, inferior colliculus; PrL, prelimbic cortex; PVN, paraventricular hypothalamic nucleus.

as an animal test for evaluating cognition in rodents (Albrechet-Souza et al., 2008). In consonant with this proposal are the results showing that scopolamine, a drug that produces learning acquisition deficit, given prior to the first exposure to the EPM, disrupts the usual behavioral strategy adopted throughout the retest performance (Carobrez \& Bertoglio, 2005).

\section{Cg1 as a target site for the anxiolytic action of the benzodiazepines}

After evaluating the neural substrates recruited during the test and retest sessions in the EPM, we investigated the loci of action of the benzodiazepine midazolam systemically injected before these conditions (Table 2) (Albrechet-Souza et al., 2009). Naive rats treated with midazolam had a significant decrease in the number of Fos-positive neurons in the $\mathrm{Cg} 1$, anterior hypothalamus nucleus (AHC) and dorsal premammillary nucleus of hypothalamus (PMD), indicating that these structures are involved in the anxiolytic effects of the benzodiazepines in the EPM (Figure 3). Cg1, as part of the $\mathrm{mPFC}$, has been suggested to play an important role in initiation and maintenance of goal-directed behaviors (Devinsky, Morrell, \& Vogt, 1995). Moreover, a number of studies have shown that the mPFC provides important projections to the AHC and PMD (Comoli, RibeiroBarbosa, \& Canteras, 2000). These hypothalamic nuclei act in concert with the ventromedial hypothalamic nucleus to form the medial hypothalamic zone, which integrates innate defensive responses to environmental threats (Canteras, 2002). Besides, chemical lesions in caudal regions of this zone significantly impair the defensive behavior expression of animals confronted with a predator, suggesting that the medial hypothalamic zone is essential for the expression of behavioral responses to environmental threats (Canteras, Chiavegatto, Ribeiro do Valle, \& Swanson, 1997).

Maze-experienced rats treated with midazolam had a significant decrease in the number of Fos-positive neurons in the $\mathrm{mPFC}$, amygdala, DMH and raphe nuclei (Figure 4). Amygdala has been reported to be important in paradigms of memory, specially related to aversive conditioning (Maren, 2008; Paré, Quirk, \& Ledoux, 2004) and there is strong evidence to suggest that the input from the ventral mPFC to the central amygdaloid nucleus is an important axis for controlling the extinction of conditioned fear (Sierra-Mercado, Corcoran, Lebron-Milad, \& Quirk, 2006). The DMH receives input from the amygdala (Bernardis \& Bellinger, 1987; LeDoux, Iwata, Cicchetti, \& Reis, 1988 ) and plays an important role in physiological defense responses (Keim \& Shekhar, 1996). Lesion in this nucleus did not change the avoidance component of the exploratory behavior in the EPM (File, Gonzalez, \& Gallant, 1999). The dorsal raphe nucleus is the major serotonergic innervation of the amygdala (Parent, Descarries, \& Beaudet, 1981) and these neurons seem to exert opposing actions on innate and

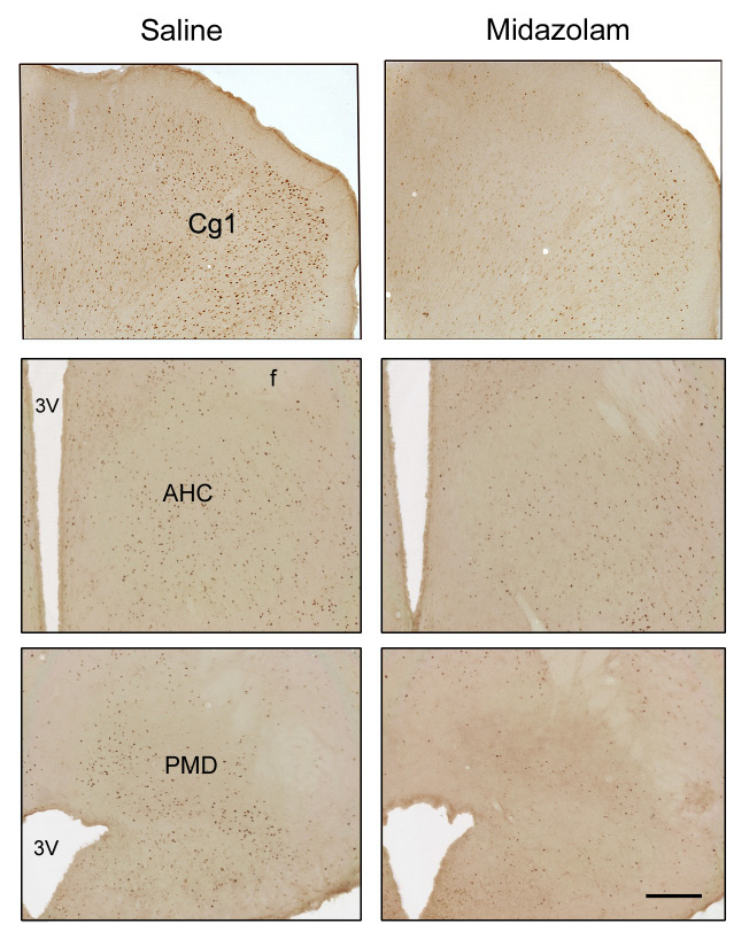

Figure 3. Representative photomicrographs showing the effects of systemically injected midazolam $(.5 \mathrm{mg} / \mathrm{kg})$ in $\mathrm{Cg} 1$, AHC and PMD Fos-immunoreactive cells (dark dots) of rats submitted to the EPM test session. Bar represents $200 \mu \mathrm{m}$ in all photomicrographs. AHC, anterior hypothalamus central; $\mathrm{Cg} 1$, cingulate cortex, area 1 ; f, fornix; PMD, dorsal premammillary nucleus; $3 \mathrm{~V}$, third ventricle. 


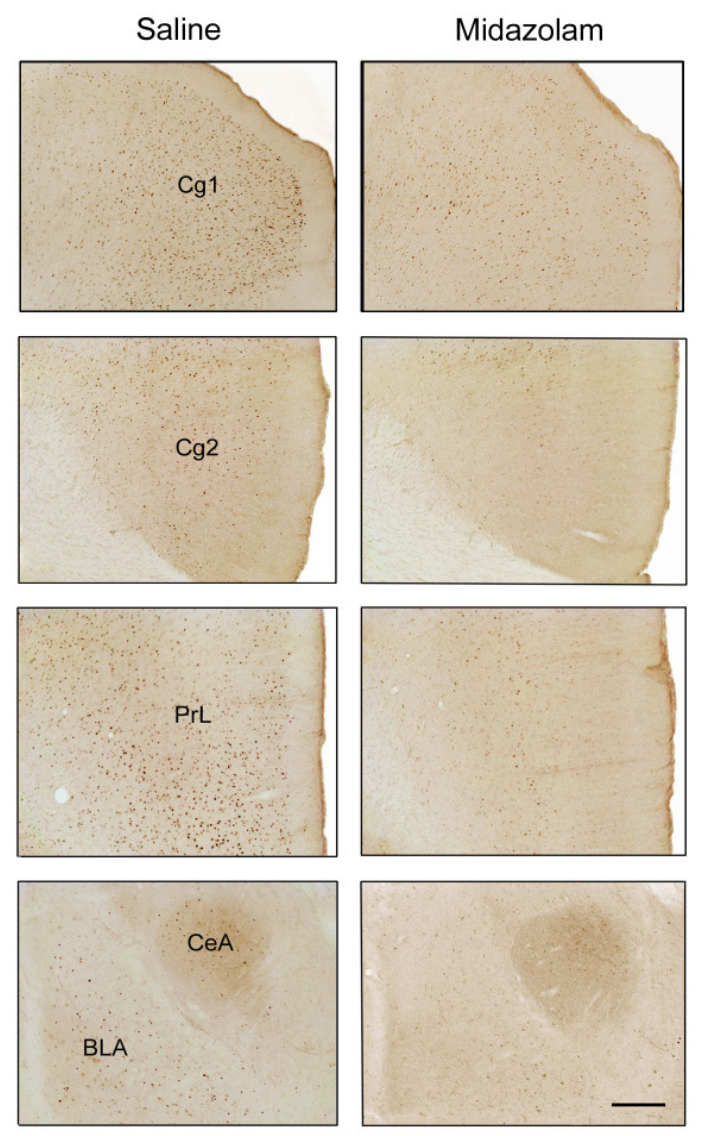

Figure 4. Representative photomicrographs showing the effects of systemically injected midazolam $(.5 \mathrm{mg} / \mathrm{kg})$ in $\mathrm{Cg} 1, \mathrm{Cg} 2$, PrL, BLA and CeA Fos-immunoreactive cells (dark dots) of rats submitted to the EPM retest session. Bar represents $200 \mu \mathrm{m}$ in all photomicrographs. BLA, basolateral amygdaloid nucleus; $\mathrm{CeA}$, central amygdaloid nucleus; $\mathrm{Cg} 1$, cingulate cortex, area 1; $\mathrm{Cg} 2$, cingulate cortex, area 2; PrL, prelimbic cortex. learned fear (Maier, Kalman, \& Grahn, 1994) whereas the serotonergic neurons of the median raphe nucleus appear to be crucial for the expression of freezing to contextual cues (Avanzi \& Brandão, 2001; Avanzi, Castilho, Andrade, \& Brandão, 1998).

Interestingly, midazolam did not change the number of Fos-positive neurons in the PVN. As we have discussed above, systemically injected midazolam decreased the plasma corticosterone levels in naive and maze-experienced rats. A possible explanation to this apparent discrepancy is that the benzodiazepine may inhibit the HPA axis in a level other than the PVN. In fact, peripheral-type of benzodiazepine receptors have been found in the mammalian pituitary gland, in both anterior and intermediate lobes, as revealed by receptor binding and autoradiographic techniques (Anderson \& Mitchell, 1994; Brown \& Martin, 1984; De Souza, Anholt, Murphy, Snyder, \& Kuhar, 1985). Moreover, the lack of changes in Fos expression does not necessarily preclude involvement of any cell group in a functional circuit (Chan, Brown, Ericsson, Kovacs, \& Sawchenko, 1993; Imaki et al., 1995).

Shah and Treit (2004) showed that the mPFC may be an important region for mediating the anxiolytic effects of benzodiazepines in naive rats submitted to the EPM. In view of the evidence that $\mathrm{Cg} 1$ was the only structure targeted by midazolam actions on the test and retest sessions and to go one step further, the benzodiazepine was bilaterally injected into this area upon both conditions (Albrechet-Souza et al., 2009). Midazolam produced the characteristic decrease of anxiety-related behaviors in naive rats, increasing the open arms entries and the time spent

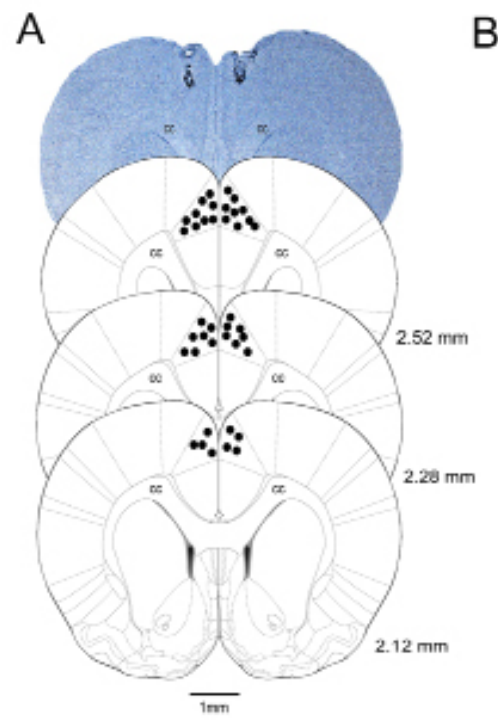

B
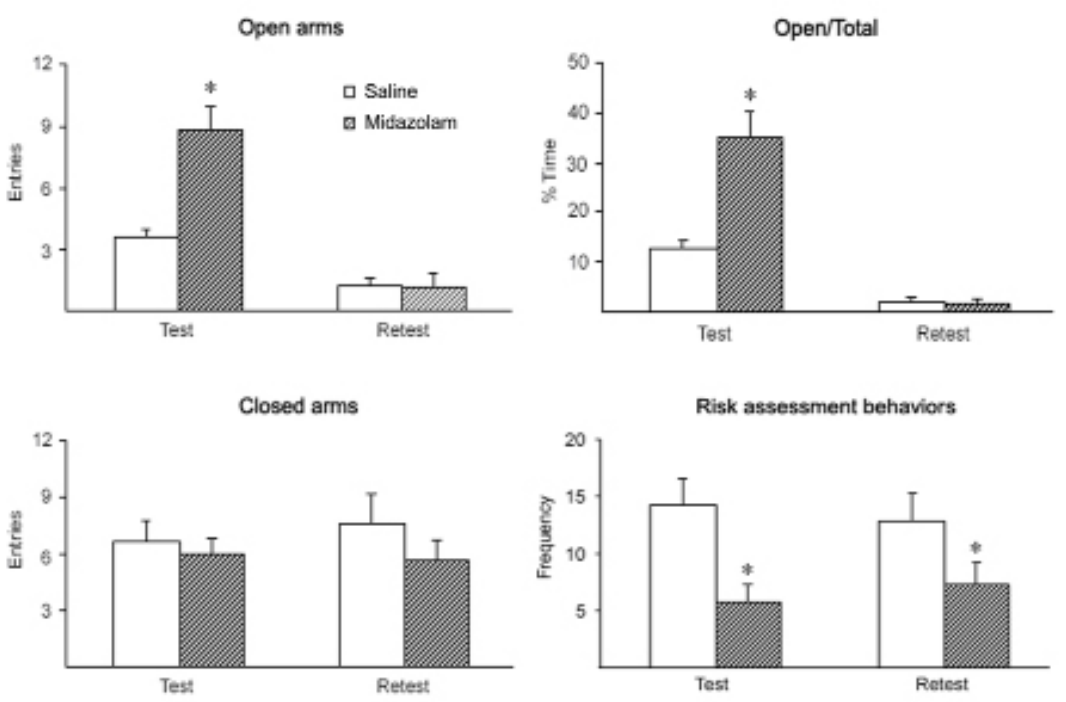

Figure 5. Exploratory behavior of rats treated with saline or midazolam $(5 \mu \mathrm{g} / .5 \mu \mathrm{l})$ intra-Cg1 and submitted to the EPM test or retest sessions (inter-trial interval was 24 hours). (A) Photomicrograph of representative sites and location of injection sites in the $\mathrm{Cg} 1$ based on the rat brain atlas of Paxinos and Watson (2005). (B) Traditional measures and risk assessment behaviors (SAP, peeping out and flat-back) of rats submitted to EPM test or retest sessions. The values are mean + SEM. * compared to saline group in the same session ( $\mathrm{p}<.05$, ANOVA followed by Duncan's test). $\mathrm{n}=6-9$ rats in each group. cc, corpus callosum. 
in these arms without changing the motor activity in the closed arms. Interestingly enough, in the same way as systemic injections, midazolam kept its effectiveness in promoting reduction of the RABs in test and retest sessions (Figure 5). To our knowledge no other limbic structure showed such reactivity to local injections of benzodiazepines. For instance, midazolam administrated into the dorsal columns of the PAG (Table 2, Figure 4) produces anxiolytic-like effects in naive, but does not change any behavioral measure in maze-experienced mice (Reis \& Canto-deSouza, 2008). In view of these data, $\mathrm{Cg} 1$ is pointed as an important locus of the anxiolytic-like action of benzodiazepines in rodents.

\section{Final comments}

Although described as a simple method for assessing anxiety responses of rodents (Pellow et al., 1985), the EPM has proven to be very complex in terms of behavioral analysis (Carobrez \& Bertoglio, 2005). This difficulty increases substantially when the EPM is used repeatedly to assess the anxiogenic/anxiolytic effects of pharmacological agents as well as the brain loci for the action of minor tranquilizers. In our studies, the EPM methodology has been refined as an animal model of anxiety looking at the behavioral, hormonal and cognitive variables in an integrated way. Thus, three main points may derive from our findings: 1) midazolam reduces the RABs and counteracts the increase in plasma corticosterone levels in rats submitted to the EPM test and retest sessions; 2) the reexposure to the maze is characterized by more prominent RABs and recruits areas involved in cognitive aspects of the fear, such as the ventral regions of the mPFC and amygdala; 3 ) the Fos immunoreactivity technique showed that $\mathrm{Cg} 1$ is the only structure targeted by midazolam on the EPM test and retest sessions and intra- $\mathrm{Cg} 1$ infusions of this compound replicated the behavioral effects of the drug systemically injected.

The results reviewed here support the view of a crucial role of the RABs in the development of the OTT and point to the $\mathrm{Cg} 1$ as an important locus for the anxiolytic-like action of benzodiazepines in rodents. Ultimately, with the present approach, it will be possible not only to refine the understanding of the EPM test, but also bring new evidence for the development and progress of current and new clinically useful animal models, which may account for the comprehension of the neurobiology of fear and anxiety.

\section{Acknowledgements}

Preparation of this review and research in our laboratory were supported by FAPESP [Proc No. 2006/06354-5]. L. Albrechet-Souza is recipient of a doctoral scholarship from CNPq.

\section{References}

Albrechet-Souza, L., Borelli, K.G., \& Brandão, M.L. (2008). Activity of the medial prefrontal cortex and amygdala underlies one-trial tolerance of rats in the elevated plus-maze. Journal of Neuroscience Methods, 169, 109-118.

Albrechet-Souza, L., Borelli, K.G., Carvalho, M.C., \& Brandão, M.L. (2009). The anterior cingulate cortex is a target structure for the anxiolytic-like effects of benzodiazepines assessed by repeated exposure to the elevated plus-maze and fos immunoreactivity. Neuroscience, 164, 387-397.

Albrechet-Souza, L., Carvalho, M.C., Franci, C.R., \& Brandão, M.L. (2007). Increases in plasma corticosterone and stretched-attend postures in rats naive and previously exposed to the elevated plusmaze are sensitive to the anxiolytic-like effects of midazolam. Hormones and Behavior, 52, 267-273.

Albrechet-Souza, L., Oliveira, A.R., De Luca, M.C.Z., Tomazini, F., Santos, N.R., \& Brandão, M.L. (2005). A comparative study with two types of elevated plus-maze (transparent vs. opaque walls) on the anxiolytic effects of midazolam, one-trial tolerance and fearinduced analgesia. Progress in Neuro-Psychopharmacology \& Biological Psychiatry, 29, 571-579.

Anderson, R.A., \& Mitchell, R. (1994). Analysis of benzodiazepine binding sites in rat pituitary gland. Brain Research, 323, 369-373.

Anseloni, V.C.Z., \& Brandão, M.L. (1997). Ethopharmacological analysis of behaviour of rats using variations of the elevated plusmaze. Behavioral Pharmacology, 8, 533-540.

Avanzi, V., \& Brandão, M.L. (2001). Activation of somatodrendritic 5-HT1A autoreceptors in the raphe nucleus disrupts the contextual conditioning in rats. Behavioural Brain Research, 126, 175-184.

Avanzi, V., Castilho, V.M., Andrade, T.G.C., \& Brandão, M.L. (1998). Regulation of contextual conditioning by the median raphe nucleus. Brain Research, 790, 178-184.

Barbalho, C.A., Canto-de-Souza, A.L., \& Nunes-de-Souza, R.L. (2009). Similar anxiolytic-like effects following intra-amygdala infusions of benzodiazepine receptor agonist and antagonist: evidence for the release of an endogenous benzodiazepine inverse agonist in mice exposed to elevated plus-maze test. Brain Research, 1267, 65-76.

Bernardis, L.L., \& Bellinger, L.L. (1987). The dorsomedial hypothalamic nucleus revisited: 1986 update. Brain Research, 434, 321-381.

Bertoglio, L.J., Anzini, C., Lino-de-Oliveira, C., \& Carobrez, A.P. (2005). Enhanced dorsolateral periaqueductal gray activity counteracts the anxiolytic response to midazolam on the elevated plus-maze Trial 2 in rats. Behavioural Brain Research, 162, 99-107.

Bertoglio, L.J., \& Carobrez, A.P. (2000). Previous maze experience required to increase open arms avoidance in rats submitted to the elevated plus-maze model of anxiety. Behavioural Brain Research, 108, 197-203.

Bertoglio, L.J., \& Carobrez A.P. (2002). Prior maze experience required to alter midazolam effects in rats submitted to the elevated plusmaze. Pharmacology, Biochemistry and Behavior, 72, 449-455.

Bertoglio, L.J., \& Carobrez A.P. (2003). Anxiolytic-like effects of NMDA/glycine-B receptor ligands are abolished during the elevated plus-maze Trial 2 in rats. Psychopharmacology, 170, 335-342.

Bertoglio, L.J., \& Carobrez A.P. (2004). Scopolamine given pre-Trial 1 prevents the one-trial tolerance phenomenon in the elevated plusmaze Trial 2. Behavioural Pharmacology, 15, 45-54.

Blanchard, D.C., Blanchard, R.J., \& Rodgers, R.J. (1991). Risk assessment and animal models of anxiety. In B. Olivier, J. Mos, \& J.L. Slangen (Eds), Animal models in Psychopharmacology (pp. 117-134). Basel: Birkauser.

Blanchard, R.J., Yudko, E.B., Rodgers, R.J., \& Blanchard, D.C. (1993). Defense system psychopharmacology: an ethological approach to the pharmacology of fear and anxiety. Behavioural Brain Research, 58, 155-165.

Borelli, K.G., \& Brandão, M.L. (2008). Effects of ovine CRF injections into the dorsomedial, dorsolateral and lateral columns of the periaqueductal gray: a functional role for the dorsomedial column. Hormones and Behavior, 53, 40-50.

Brown, C., \& Martin, I.L. (1984). Autoradiographic localization of benzodiazepine receptors in the rat anterior pituitary gland. European Journal of Pharmacology, 102, 563-564.

Canteras, N.S. (2002). The medial hypothalamic defensive system: hodological organization and functional implications. Pharmacology, Biochemistry and Behavior, 71, 481-491.

Canteras, N.S., Chiavegatto, S., Ribeiro do Valle, L.E., \& Swanson, 
L.W. (1997). Severe reduction of defensive behavior to a predator by discrete hypothalamic chemical lesions. Brain Research Bulletin, 44, 297-305.

Carobrez, A.P., \& Bertoglio, L.J. (2005). Ethological and temporal analyses of anxiety-like behavior: the elevated plus-maze model 20 years on. Neuroscience and Biobehavioral Reviews, 29, 1193-1205.

Carvalho, M.C., Albrechet-Souza, L., Masson, S., \& Brandão, M.L. (2005). Changes in the biogenic amine content of the prefrontal cortex, amygdala, dorsal hippocampus, and nucleus accumbens of rats submitted to single and repeated sessions of the elevated plusmaze test (Figure 1). Brazilian Journal of Medical and Biological Research, 38, 1857-1866.

Chan, R.K.W., Brown, E.R., Ericsson, A., Kovacs, K.J., \& Sawchenko, P.E. (1993). A comparison of two immediate early genes, c-fos and NGFI-B, as markers for functional activation in stress-related neuroendocrine circuitry. The Journal of Neuroscience, 13, 51265138.

Cole, J.C., \& Rodgers, R.J. (1993). An ethological analysis of chlordiazepoxide and bretazenil (Ro16-6028) in the murine elevated plus-maze. Behavioral Pharmacology, 4, 573-580.

Comoli, E., Ribeiro-Barbosa, E.R., \& Canteras, N.S. (2000). Afferent connections of the dorsal premammillary nucleus. Journal of Comparative Neurology, 423, 83-98.

Cruz-Morales, S.E., Santos, N.R., \& Brandão, M.L. (2002). One-trial tolerance to midazolam is due to enhancement of fear and reduction of anxiolytic-sensitive behaviors in the elevated plus-maze retest in the rat. Pharmacology, Biochemistry and Behavior, 72, 973-978.

Dal-Cól, L., Orlandi-Pereira, V.P., Rosa, A.V., Calixto, A.P., Carobrez, A.P., \& Faria M.S. (2003). Lack of midazolam-induced anxiolysis in the plus-maze Trial 2 is dependent on the length of Trial 1. Pharmacology, Biochemistry and Behavior, 74, 395-400.

Dawson, G.R., Crawford, S.P., Stanhope, K.J., Iversen, S.D., \& Tricklebank, M.D. (1994). One-trial tolerance to the effects of chlordiazepoxide on the elevated plus-maze may be due to locomotor habituation, not repeated drug exposure. Psychopharmacology, $113,570-572$.

De Quervain, D.J.F., Roozendaal, B., \& McGaugh, J.L. (1998). Stress and glucocorticoids impair retrieval of long-term spatial memory. Nature 394, 787-790.

De Souza, E.B., Anholt, R.R.H., Murphy, K.M.M., Snyder, S.H., \& Kuhar, M.K. (1985). Peripheral-type benzodiazepine receptors in endocrine organs: autoradiographic localization in rat pituitary, adrenal and testis. Endocrinology, 116, 567-573.

Devinsky, O., Morrell, M.J., \& Vogt, B.A. (1995). Contributions of anterior cingulate cortex to behaviour. Brain, 118, 279-306.

File, S.E. (1990). One-trial tolerance to the anxiolytic effects of chlordiazepoxide in the plus-maze. Psychopharmacology, 100, 281-282.

File, S.E. (1993). The interplay of learning and anxiety in the elevated plus-maze. Behavioural Brain Research, 58, 199-202.

File, S.E., Gonzalez, L.E., \& Gallant, R. (1999). Role of the dorsomedial hypothalamus in mediating the response to benzodiazepines on trial 2 in the elevated plus-maze test of anxiety. Neuropsychopharmacology, 21, 312-320.

File, S.E., Mabutt, P.S., \& Hitchott, P.K. (1990). Characterization of the phenomenon of 'one-trial tolerance' to the anxiolytic effects of chlordiazepoxide in the elevated plus-maze. Psychopharmacology, 102, 91-101.

File, S.E., Zangrossi, H., Sanders, F.L., \& Mabbutt, P.S. (1994). Raised corticosterone in the rat after exposure to the elevated plus-maze. Psychopharmacology, 113, 543-546.

File S.E., Zangrossi, H., Viana, M., \& Graeff, F.G. (1993). Trial 2 in the elevated plus-maze: a different form of fear? Psychopharmacology, 111, 491-494.

Gonzalez, L.E., \& File, S.E. (1997). A five-minute experience in the elevated plus-maze alters the state of the benzodiazepine receptor in the dorsal raphe nucleus. The Journal of Neuroscience, 17, 1505-1511.

Griebel, G., Rodgers, R.J., Perrault, G., \& Sanger, D.J. (1997). Risk assessment behaviour: evaluation of utility in the study of 5-HTrelated drugs in the rat elevated plus-maze test. Pharmacology, Biochemistry and Behavior, 57, 817-827.

Handley, S.L., \& Mithani, S. (1984). Effects of alpha-adrenoreceptor agonist in a maze-exploration model of "fear-motivated behaviour". Naunyn-Scmiedeberg's Archives of Pharmacology, 327, 1-5.

Heidbreder, C.A., \& Groenewegen, H.J. (2003). The medial prefrontal cortex in the rat: evidence for a dorso-ventral distinction based upon functional and anatomical characteristics. Neuroscience and Biobehavioral Reviews, 27, 555-579.

Holmes, A., \& Rodgers, R. J. (1998). Responses of Swiss-Webster mice to repeated plus-maze as experience: further evidence for qualitative shift in emotional state. Pharmacology, Biochemistry and Behavior, 60, 473-488.

Holschneider, D.P., Yang, J., Sadler, T.R., Nguyen, P.T., Givrad, T.K., \& Maarek, J.M.I. (2006). Mapping cerebral blood flow changes during auditory-cued conditioned fear in the nontethered, nonrestrained rat. Neuroimage, 29, 1344-1358.

Imaki, T., Wang, X.Q., Shibasaki, T., Harada, S., Chikada, N., Takahashi, C., Naruse, M., \& Demura, H. (1995). Chlordiazepoxide attenuates stress-induced activation of neurons, corticotropin-releasing factor (CRF) gene transcription and CRF biosynthesis in the paraventricular nucleus (PVN). Molecular Brain Research, 32, 261-270.

Keim, S.R., \& Shekhar, A. (1996). The effects of GABAA receptor blockade in the dorsomedial hypothalamic nucleus on corticotrophin $(\mathrm{ACTH})$ and corticosterone secretion in male rats. Brain Research, 739, 46-51.

LeDoux, J.E., Iwata, J., Cicchetti, P., \& Reis, D.J. (1988). Different projections of the central amygdaloid nucleus mediate autonomic and behavioral correlates of conditioned fear. The Journal of Neuroscience, 8, 2517-2529.

Lister, R.G. (1987). The use of a plus-maze to measure anxiety in the mouse. Psychopharmacology, 92, 180-185.

Maier, S.F., Kalman, B.A., \& Grahn, R.E. (1994). Chlordiazepoxide microinjected into the region of the dorsal raphe nucleus eliminates the interference with escape responding produced by inescapable shock whether administered before inescapable shock or escape testing. Behavioural Neuroscience, 108, 121-130.

Maren, S. (2008). Pavlovian fear conditioning as a behavioral assay for hippocampus and amygdala function: cautions and caveats. European Journal of Neuroscience, 28, 1661-1666.

Mason, W. (1968). "Over-all” hormonal balance as a key to endocrine organization. Psychosomatic Medicine 30, 791-808.

Mikics, E., Barsy, B., Barsvari, B., \& Haller, J. (2005). Behavioral specificity of non-genomic glucocorticoid effects in rats: effects on risk assessment in the elevated plus-maze and the open-field. Hormones and Behavior, 48, 152-162.

Milad, M.R., \& Quirk, G.J. (2002). Neurons in medial prefrontal cortex signal memory for fear extinction. Nature, 420, 70-74.

Mobbs, D., Petrovic, P., Marchant, J.L., Hassabis, D., Weiskopf, N., Seymour, B., Dolan, R.J., \& Frith, C.D. (2007). When fear is near: threat imminence elicits prefrontal-periaqueductal gray shifts in humans. Science, 317, 1079-1083.

Morgan, M. A., Romanski, L. M., \& LeDoux, J. E. (1993). Extinction of emotional learning: Contribution of medial prefrontal cortex. Neuroscience Letters, 163, 109-113.

Morgan, M.A., \& LeDoux, J.E. (1995). Differential contribution of dorsal and ventral medial prefrontal cortex to the acquisition and extinction of conditioned fear in rats. Behavioral Neuroscience, 109, 681-688.

Paré, D., Quirk, G.J., \& Ledoux, J.E. (2004). New vistas on amygdala networks in conditioned fear. Journal of Neurophysiology, 92, 1-9.

Parent, A., Descarries, L., \& Beaudet, A. (1981). Organization of ascending serotonin systems in the adult rat brain. A radioautographic study after intraventricular administration of [3H]5-hydroxytryptamine. Neuroscience, 6, 115-138.

Paxinos, G., \& Watson, C. (2005). The rat brain in stereotaxic coordinates. San Diego: Elsevier Academic Press.

Pellow, S., Chopin, P., File, S.E., \& Briley, M. (1985). Validation of open-closed arm entries in the elevated plus-maze as a measure of anxiety in the rat. Journal of Neuroscience Methods, 14, 149-167.

Pereira, J.K.D., Vieira, R.J., Konishi, C.T., Ribeiro, R.A., \& FrussaFilho, R. (1999). The phenomenon of 'one-trial tolerance' to the anxiolytic effect of chlordiazepoxide in the elevated plus-maze is abolished by the introduction of a motivational conflict situation. Life Science, 65, 101-107.

Pezze, M.A., Bast, T., \& Feldon, J. (2003). Significance of dopamine transmission in the rat medial prefrontal cortex for conditioned fear. Cerebral Cortex, 13, 371-380.

Reis, L.M., \& Canto-de-Souza, A. (2008). Intra-periaqueductal gray matter injections of midazolam fail to alter anxiety in plus-maze experienced mice. Brain Research, 1231, 93-102.

Risbrough, B., \& Stein, M.B. (2006). Role of corticotropin-releasing 
factor in anxiety disorders: a translational research perspective. Hormones and Behavior, 50, 550-561.

Rivier, C.L., Grigoriadis, D.E., \& Rivier, J.E. (2003). Role of corticotropin-releasing factor receptors type 1 and 2 in modulating the rat adrenocorticotropin response to stressors. Endocrinology, 144, 2396-2403.

Rodgers, R.J. (1997). Animal models of 'anxiety': where next? Behavioral Pharmacology, 8, 477-496.

Rodgers, R.J., Cao, B.J., Dalvi, A., \& Holmes, A. (1997). Animal models of anxiety: an ethological perspective. Brazilian Journal of Medical and Biological Research, 30, 289-304.

Rodgers, R.J., \& Cole, J.C. (1994). The elevated plus-maze: pharmacology, methodology and ethology. In S.J. Cooper, \& C.A. Hendrie (Eds), Ethology and Psychopharmacology (pp. 9-44). Wiley: Chichester.

Rodgers, R.J., Haller, J., Holmes, A., Halasz, J., Walton, T.J., \& Brain, P.F. (1999). Corticosterone response to the plus-maze: high correlation with risk assessment in rats and mice. Physiology and Behavior, 68, 47-53.

Rodgers, R.J., \& Johnson, J.T. (1995). Factor analysis of spatiotemporal and ethological measures in the murine elevated plus-maze test of anxiety. Pharmacology, Biochemistry and Behavior, 52, 297-303.

Roozendaal, B., Bohus, B., \& McGaugh, J.L. (1996). Dose-dependent suppression of adrenocortical activity with metyrapone: Effects on emotion and memory. Psychoneuroendcocrinology, 21, 681-693.

Setem, J., Pinheiro, A.P., Motta, V.A., Morato, S., \& Cruz, A.P.M. (1999). Ethopharmacological analysis of 5-HT ligands on the rat elevated plus-maze. Pharmacology, Biochemistry and Behavior, $62,515-521$.

Shah, A.A., \& Treit, D. (2004). Infusions of midazolam into the medial prefrontal cortex produce anxiolytic effects in the elevated plus-maze and shock-probe burying tests. Brain Research, 996, 31-40.

Siegel, A., \& Chabora, J. (1971). Effects of electrical stimulation of the cingulate gyrus upon attack behavior elicited from the hypothalamus in the rat. Brain Research, 32, 169-177.

Siegel, A., Edinger, H., \& Lowenthal, H. (1974). Effects of electrical stimulation of the medial aspect of the prefrontal cortex upon attack behavior in cats. Brain Research, 66, 467-479.

Sierra-Mercado, D.J., Corcoran, K.A., Lebron-Milad, K., \& Quirk, G.J. (2006). Inactivation of the ventromedial prefrontal cortex reduces expression of conditioned fear and impairs subsequent recall of extinction. European Journal of Neuroscience, 24, 1751-1758.

Silveira, M.C., Sandner, G., \& Graeff, F.G. (1993). Induction of Fos immunoreactivity in the brain by exposure to the elevated plusmaze. Behavioural Brain Research, 56, 115-118.

Singewald, N. (2007). Altered brain activity processing in high-anxiety rodents revealed by challenge paradigms and functional mapping. Neuroscience and Biobehavioral Reviews, 31, 18-40.

Stern, C.A., Carobrez, A.P., \& Bertoglio, J.L. (2008). A versive learning as a mechanism for lack of repeated anxiolytic-like effect in the elevated plus-maze. Pharmacology, Biochemistry and Behavior, 90, 545-550.

Treit, D., Menard, J., \& Royan, C. (1993). Anxiogenic stimuli in the elevated plus-maze. Pharmacology, Biochemistry and Behavior, 44, 463-469

Vale, W.W., Spiess, J., Rivier C., \& Rivier, J. (1981). Characterization of a 41-residue ovine hypothalamic peptide that stimulates secretion of corticotropin and beta-endorphin. Science, 18, 1394-1397.

Vouimba, R.M., Garcia, R., Baudry, M., \& Thompson, R.F. (2000). Potentiation of conditioned freezing following dorsomedial prefrontal cortex lesions does not interfere with fear reduction in mice. Behavioral Neuroscience, 114, 720-724.

Yang, M., Farrokhi, C., Vasconcellos, A., Blanchard, R.J., \& Blanchard, D.C. (2006). Central infusion of ovine CRF (oCRF) potentiates defensive behaviors in CD-1 mice in the Mouse Defense Test Battery (MDTB). Behavioural Brain Research, 17, 1-8.

Zanoveli, J.M., Ferreira-Netto, C., \& Brandão, M.L. (2007). Conditioned place aversion organized in the dorsal periaqueductal gray recruits the laterodorsal nucleus of thalamus and basolateral amygdala. Experimental Neurology, 208, 127-136.

\section{Abbreviations}

$\mathrm{ACTH}$, adrenocorticotropin hormone; $\mathrm{AHC}$, anterior hypothalamus central; BLA, basolateral amygdaloid nucleus; CA1, field of dorsal hippocampus; CA2, field of dorsal hippocampus; CA3, field of dorsal hippocampus; $\mathrm{CeA}$, central amygdaloid nucleus; $\mathrm{Cg} 1$, cingulate cortex, area $1 ; \mathrm{Cg} 2$, cingulate cortex, area $2 ; \mathrm{CRF}$, corticotropinreleasing factor; $\mathrm{DMH}$, dorsomedial hypothalamus; DMPAG, dorsomedial periaqueductal gray; DLPAG, dorsolateral periaqueductal gray; DRN, dorsal raphe nucleus; EPM, elevated plus-maze; HPA: hypothalamicpituitary-adrenal; IC, inferior colliculus; IL, infralimbic cortex; LC, locus coeruleus; LPAG, lateral periaqueductal gray; MeA, medial amygdaloid nucleus; MnR, median raphe nucleus; mPFC, medial prefrontal cortex; PAG, periaqueductal gray matter; $\mathrm{PVN}$, paraventricular hypothalamic nucleus; PMD, dorsal premammillary nucleus; PrL, prelimbic cortex; RABs, risk assessment behaviors; VLPAG, ventrolateral periaqueductal gray. 